\title{
Duas atividades experimentais sobre associações de espelhos e lentes inspiradas por questões de vestibulares ${ }^{+*}$
}

Jair Lúcio Prados Ribeiro ${ }^{1}$

Doutorando do Programa de Pós-Graduação em Educação em Ciências

Universidade de Brasília

Brasília - DF

\section{Resumo}

São descritas duas atividades experimentais envolvendo associações de espelhos e lentes, delineadas a partir de questões de exames vestibulares. As questões são apresentadas no formato original e resolvidas de forma algébrica. A seguir, as montagens experimentais são apresentadas e discutidas. Propõe-se que a utilização das atividades experimentais em correlação direta com os exercícios didáticos possa contribuir para a aprendizagem.

Palavras-chave: Óptica geométrica; Espelho; Lente; Experimento.

\begin{abstract}
Two experimental activities involving mirrors and lenses associations, outlined from college admission exams, are described. The questions are presented in the original format and solved algebraically. Then, the experimental setups are presented and discussed. It is proposed that the use of experimental activities in direct relation with didactic exercises can contribute to learning.
\end{abstract}

Keywords: Geometrical Optics; Mirror; Lens; Experiment.

\footnotetext{
${ }^{+}$Two experimental activities on mirrors and lenses associations inspired by college admission exams

* Recebido: junho de 2015.

Aceito: outubro de 2015.

${ }^{1}$ E-mail: jairlucio@gmail.com
} 


\section{Origem do questionamento}

A resolução de exercícios didáticos pode ser considerada indissociável do planejamento e execução de um curso de física no ensino médio. Corroborando com essa visão, os livros didáticos voltados para essa fase de ensino costumam trazer grandes acervos de problemas e questões retiradas de exames vestibulares tradicionais ou do Exame Nacional do Ensino Médio (ENEM). Nesse aspecto, montagens experimentais de verificação das situações presentes em exercícios didáticos ou extraídos de exames seletivos em demonstrações experimentais podem se revelar ferramentas didáticas interessantes, podendo vir a ajudar os estudantes a compreender com mais facilidade a solução algébrica ou geométrica, além de poder comprovar ou refutar a validade das afirmações do enunciado.

Concepções equivocadas apresentadas em problemas de processos seletivos são discutidas em trabalhos recentes: Rodrigues (2014) mostra, a partir de uma revisão teórica, que uma questão do ENEM 2013 versando sobre conceitos de hidrostática apresenta respostas incoerentes com relação aos preceitos físicos, fato também passível de verificação por via experimental. Já Silveira et al. (2015) demonstram que uma tradicional questão de mecânica (barco a vela movido com um ventilador direcionado para a vela), sempre considerada em livros didáticos como fisicamente impossível, se revela como viável. Os autores conduziram uma explanação teórica sobre o problema didático e construíram um modelo experimental para testar suas afirmações. $O$ trabalho presente lida com situações presentes em problemas didáticos de óptica geométrica, mas buscando demonstrar a validade dos mesmos ao invés de refutá-los.

Em um conjunto de cinco turmas do $2^{\circ}$ ano do ensino médio de uma escola particular em Brasília (DF), após a apresentação do tratamento geométrico e matemático das lentes esféricas e de suas associações, foi conduzida a resolução de problemas-tipo e então foram propostos alguns exercícios didáticos aos estudantes. Uma das questões selecionadas, presente em um exame vestibular (UFES, 2004), lidava com a situação de um objeto colocado entre uma lente convergente e um espelho côncavo, para o qual duas imagens do mesmo são projetadas em um anteparo, questionando-se a distância do objeto ao espelho para que esse fato ocorra. O enunciado original encontra-se a seguir. A figura original do exercício tinha baixa qualidade e apresentava alto grau de pixelização, razão pela qual optamos por reconstruí-la (Fig. 1) para esse artigo.

Uma lente convergente, de distância focal $0,75 \mathrm{~cm}$, está situada $5 \mathrm{~cm}$ à frente de um espelho côncavo, de distância focal $1 \mathrm{~cm}$. Um anteparo é colocado como mostra a Fig. 1 .

Um objeto é colocado entre o espelho e a lente, de tal modo que duas imagens são formadas no anteparo, ambas de mesmo tamanho. A distância entre o objeto e o espelho é de:
a) $0,5 \mathrm{~cm}$
b) $1 \mathrm{~cm}$
c) $1,5 \mathrm{~cm}$
d) $2 \mathrm{~cm}$ (correta) 
e) Não existe uma posição onde isso seja possível.

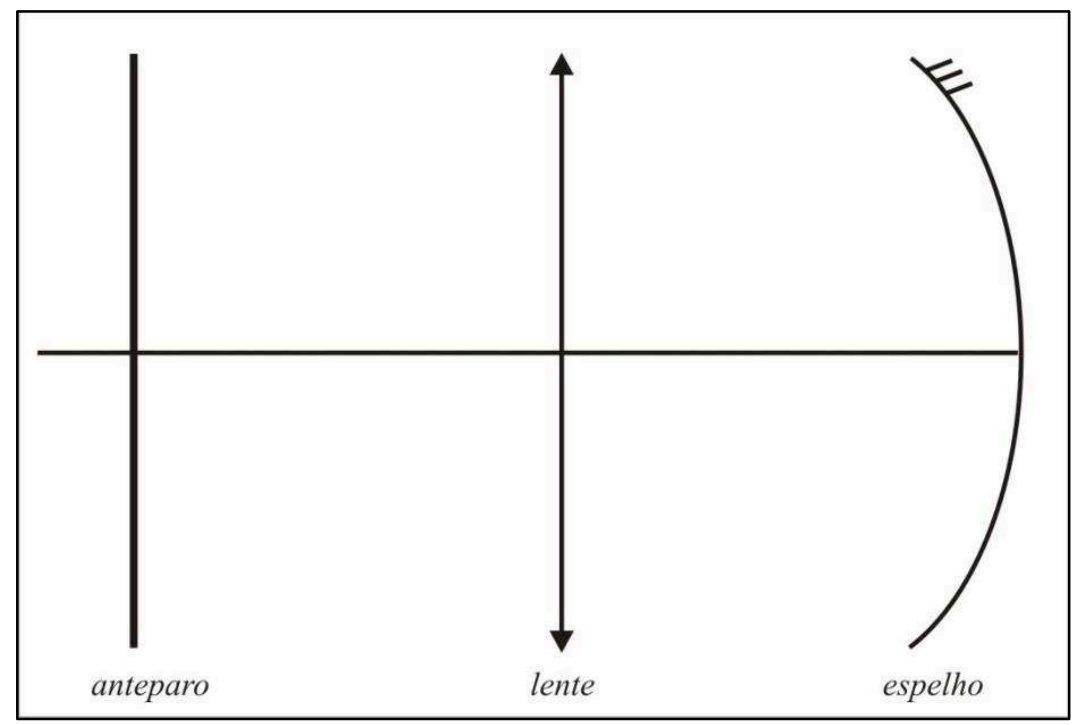

Fig. 1 - Reconstrução da figura original da questão transformada na Atividade A.

A opção correta é a letra $d$ : nessa situação, o objeto deve estar localizado sobre o centro do espelho côncavo para que as imagens citadas sejam verificadas. Entretanto, o desenvolvimento algébrico permite concluir que há outra posição do objeto, bem próxima ao espelho, para a qual também é conjugada uma segunda imagem no anteparo, quase superposta à primeira. Essa resposta foi desconsiderada pelo examinador.

Na etapa de correção dos exercícios pelo professor, a resolução dessa questão se revelou estéril e mesmo monótona em algumas turmas, enquanto o exercício foi considerado intrigante por outras. Nesses últimos grupos, os estudantes se recusaram a crer que a situação descrita no problema (a projeção de duas imagens de mesmo tamanho) fosse possível. A fim de sanar essa bem-vinda curiosidade, concebemos uma atividade experimental simples, chamada por Atividade A nesse artigo, passível de utilização tanto de forma demonstrativa quanto interativa, a fim de buscar uma contraparte realista da situação exposta no exercício, e assim contribuindo para sua correta interpretação por parte dos estudantes.

Durante a pesquisa para desenvolvimento da atividade experimental, encontramos outra questão versando sobre o tema da formação de imagens em associações de elementos ópticos, presente em outro processo seletivo (ITA, 1997), a qual está reproduzida a seguir. Novamente, a figura original da questão se apresentava inadequada e foi refeita.

Um espelho plano está colocado em frente de um espelho côncavo, perpendicularmente ao eixo principal (Fig. 2). Uma fonte luminosa A, centrada no eixo principal entre os dois espelhos, emite raios que se refletem sucessivamente sobre os dois espelhos e formam sobre a própria fonte A, uma imagem real da mesma. O raio de curvatura do espelho é $40 \mathrm{~cm}$ 
e a distância do centro da fonte A até o centro do espelho esférico é de $30 \mathrm{~cm}$. A distância d do espelho plano até o centro do espelho côncavo é, então:

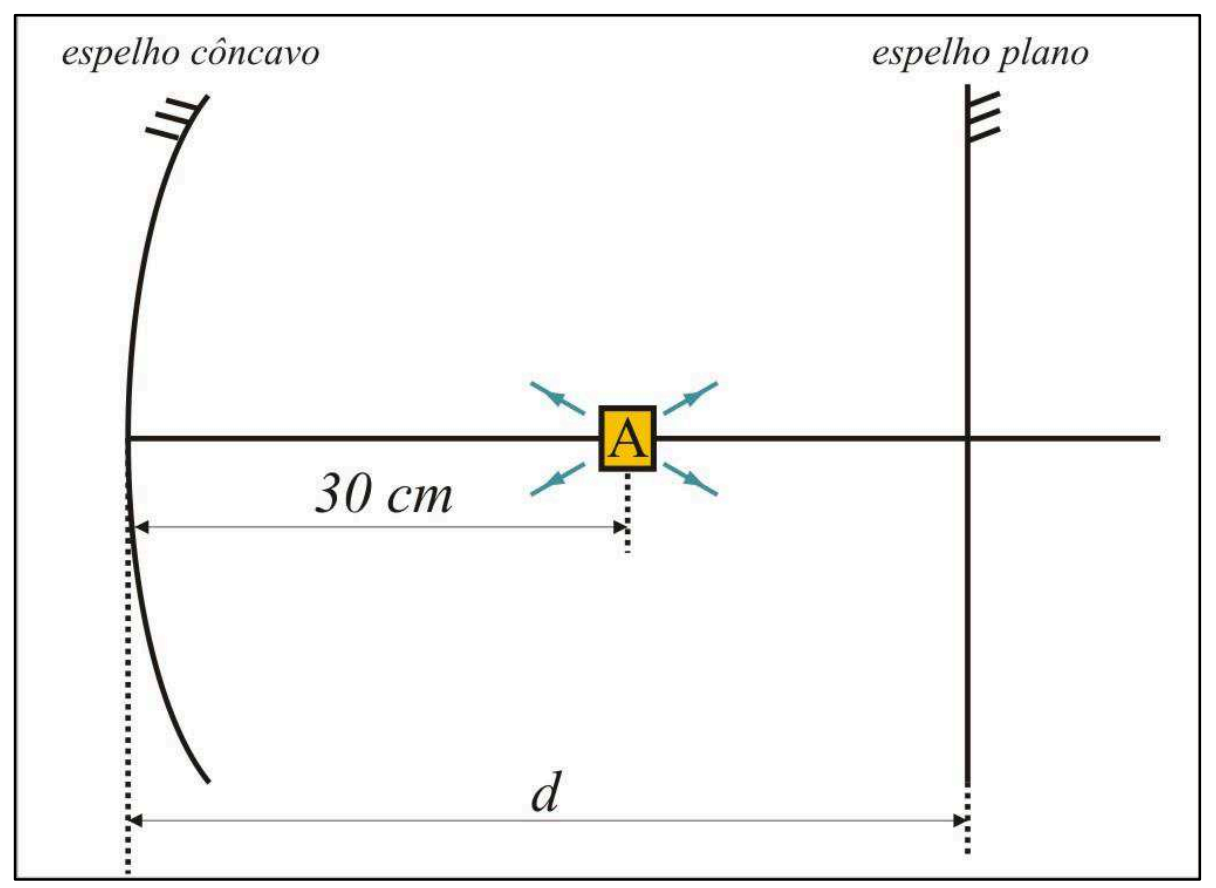

Fig. 2 - Reconstrução da figura original da questão transformada na Atividade B.
a) $20 \mathrm{~cm}$
b) $30 \mathrm{~cm}$
c) $40 \mathrm{~cm}$
d) $45 \mathrm{~cm}$ (correta)
e) $50 \mathrm{~cm}$

Como o material necessário para uma demonstração experimental é similar àquele requerido pela primeira questão, necessitando apenas da substituição da lente convergente por um espelho plano, decidimos recriar de forma experimental também a situação exposta nesse segundo exercício (chamada nesse trabalho de Atividade $B$ ) para fins de ampliação da discussão com os estudantes. Ambas as atividades foram desenvolvidas de forma demonstrativa em um encontro posterior com as turmas no laboratório de física, devido às grandes dimensões necessárias para a mesa que serviu de apoio para os elementos ópticos.

Os dois exercícios que serviram de base para a pesquisa lidam com associações de elementos ópticos: na Atividade A, há uma lente convergente e um espelho côncavo, enquanto na Atividade B, há um espelho plano e outro côncavo. Não encontramos na literatura sugestões de experimentos idênticos aos que concebemos nesse trabalho. O trabalho de Silva (2012), por exemplo, aborda de forma algébrica e geométrica diversas associações de dois espelhos, mas não trata do caso particular de espelhos côncavos e planos associados. Frisa-se, entretanto, que 
o grau de profundidade algébrica presente no artigo citado se assemelha ao constante no nosso trabalho, com o uso das equações da óptica gaussiana e a aproximação de raios paraxiais.

Já o artigo de Silveira et al. (2004) representa uma associação entre um espelho côncavo e uma lente convergente (o próprio olho humano), com um objeto posicionado entre ambos, de forma muito semelhante à Atividade A. Entretanto, a leitura do artigo mostra que a preocupação do autor diverge da nossa: a possibilidade da existência de uma dupla imagem nem mesmo é citada. A proposta dos autores, entretanto, se assemelha à nossa ao citar um exercício didático retirado de um exame vestibular, que apresenta duplicidade de resposta.

\section{Tratamento geométrico e algébrico}

A óptica geométrica é trabalhada no ensino médio a partir das condições de aproximação de Gauss. Uma vantagem desse tratamento algébrico reside na semelhança entre as equações que descrevem a formação de imagens em espelhos e lentes: adotando-se um referencial adequado, as mesmas equações podem ser usadas para quaisquer desses sistemas ópticos. As expressões podem ser encontradas em livros didáticos de física do ensino médio (e.g. PIETROCOLA et al., 2011; RAMALHO et al., 2007; SILVA; BARRETO, 2008). As dimensões relevantes nos modelos geométricos válidos para lentes e espelhos são: a distância de um objeto a um sistema óptico ( $p)$, a distância da imagem conjugada até esse mesmo sistema ( $p$ '), a distância focal $(f)$, o tamanho do objeto $(o)$ e da sua imagem $(i)$.

As condições de aproximação gaussianas para sistemas refletores (espelhos) e refratores (lentes delgadas) envolvem a consideração de raios paraxiais, ou seja, muito próximos ao eixo principal desses elementos. A equação dos pontos conjugados e a equação do aumento linear podem ser demonstradas a partir dessa condição aproximativa para ambos os tipos de sistemas. Tais demonstrações não estão incluídas nesse trabalho, por estarem amplamente disponíveis na literatura (ZÍLIO, 2009; HALLIDAY et al., 2011; HETCH, 2002; NUSSENZVEIG, 1998).

Em problemas didáticos de óptica, os modelos geométricos e algébricos podem ser vistos como complementares. Não por acaso, uma adequada representação geométrica pode facilitar a solução de problemas nesse tópico de estudo. Apresentamos a seguir as resoluções desenvolvidas para as questões desenvolvidas em cada atividade experimental.

\section{II.1 Solução algébrica e geométrica para a Atividade A}

Tanto para uma lente quanto para um espelho, são válidas as seguintes relações, advindas das expressões gaussianas:

$$
\begin{aligned}
p^{\prime} & =\frac{f . p}{p-f} \\
i & =\frac{f . o}{f-p}
\end{aligned}
$$


O objeto está localizado à distância $b$ do centro óptico da lente e $c$ do vértice do espelho côncavo de distância focal $f_{E}$. A imagem conjugada apenas pela lente convergente, de distância focal $f_{L}$, é projetada em uma tela disposta a uma distância $a$ da lente, e possui tamanho $i_{1}$.

A partir das equações 1 e 2 , vem:

$$
\begin{aligned}
& a=\frac{f_{L} \cdot b}{b-f_{L}} \\
& i_{1}=\frac{f_{L} \cdot o}{f_{L}-b}
\end{aligned}
$$

A formação da segunda imagem projetada envolve um processo mais elaborado: raios advindos do objeto refletem primeiro no espelho, formando uma imagem (não projetada) de tamanho $i_{E}$ e localizada a uma distância $p_{E}^{\prime}$ do espelho. Para essa imagem, são válidas as relações:

$$
\begin{aligned}
& p_{E}^{\prime}=\frac{f_{E} \cdot c}{c-f_{E}} \\
& i_{E}=\frac{f_{E} \cdot o}{f_{E}-c}
\end{aligned}
$$

Considerando que a imagem $i_{E}$ atua como um novo objeto óptico para a lente, é formada a segunda imagem projetada na tela, com tamanho $i_{2}$, dado por:

$$
i_{2}=\frac{f_{L} \cdot i_{E}}{f_{L}-\left(b+c-p_{E}^{\prime}\right)}
$$

O problema didático em estudo afirma que duas imagens são projetadas na mesma tela, com o mesmo tamanho, mas não indica se elas possuem a mesma orientação; assim, devemos considerar $\left|i_{1}\right|=\left|i_{2}\right|$. Assim, temos duas possibilidades:

Solução $1: i_{2}=i_{1}$; assim:

$$
\frac{f_{L} \cdot i_{E}}{f_{L}-\left(b+c-p_{E}^{\prime}\right)}=\frac{f_{L} \cdot o}{f_{L}-b}
$$

Considerando um sistema formado pelas equações 6 e 8, verifica-se que a solução possível seria $i_{E}=o$ e $c=p_{E}^{\prime}=0$. Tal resposta leva à suposição de um objeto que, no limite, toca o espelho $(c=0)$. Essa condição produziria uma imagem virtual do mesmo tamanho e orientação do objeto, praticamente na mesma posição que este, se desprezada a espessura do vidro do espelho.

Essa imagem virtual é o novo objeto real da lente, com o mesmo tamanho deste, e por estar praticamente na mesma posição do objeto original, conjuga uma imagem $i_{2}$ do mesmo tamanho $i_{1}$, no mesmo anteparo. Essa situação é inviável na prática, pois as duas imagens projetadas estão quase superpostas e não é possível diferenciá-las. Essa superposição, entretanto, produz uma imagem mais brilhante, mas não necessariamente mais nítida, pois mesmo uma pequena espessura do espelho já faz com que as duas imagens projetadas não tenham o mesmo 
tamanho, além da segunda $\left(i_{2}\right)$ estar parcialmente desfocada, pois ela se formaria antes do anteparo. Apesar de desconsiderada pelo examinador, essa solução foi testada no nosso experimento.

Solução $2: i_{2}=-i_{1}$; assim:

$$
\frac{f_{L} \cdot i_{E}}{f_{L}-\left(b+c-p_{E}^{\prime}\right)}=\frac{-f_{L} \cdot o}{f_{L}-b}
$$

Nesse caso, o sistema formado pelas eq. 6 e eq. 9 aponta para $i_{E}=-o$ e $c=2 f_{E}$, o que significa que o objeto deveria estar posicionado exatamente sobre o centro de curvatura do espelho. Sua imagem estaria situada nesse mesmo ponto, com igual tamanho, mas orientação oposta (invertida), levando a uma imagem final "direita" $i_{2}$ (na realidade, invertida duas vezes) conjugada pela lente, projetada acima da imagem $i_{1}$, no mesmo anteparo.

Essa segunda opção de resolução se revela a esperada pelo examinador, e permite inferir que a distância entre a lente e o objeto não possui influência na conjugação das duas imagens, interferindo apenas na localização adequada do anteparo (a), conforme aponta a eq. 3 .

A solução apresentada para os estudantes, entretanto, pode exibir caráter apenas geométrico. Conhecida a propriedade de que um objeto disposto sobre o centro de um espelho côncavo irá conjugar uma imagem de mesmo tamanho, invertida e também sobre o centro, é mais simples argumentar a favor da projeção de duas imagens de mesmo tamanho sobre o anteparo (a partir da igualdade entre o objeto original e essa imagem intermediária) que conduzir a demonstração algébrica acima. A Fig. 3 representa a solução geométrica, para a qual foi buscada uma demonstração experimental na Atividade A.

\section{II.2. Solução algébrica e geométrica para a Atividade $B$}

Nesse exercício, temos um espelho plano em frente a um espelho côncavo, e um objeto disposto entre os mesmos. A distância entre os dois espelhos é $d$, e considera-se a distância entre o objeto e o espelho côncavo igual a $e$, conforme mostrado na Fig. 4.

A imagem virtual conjugada pelo espelho plano $\left(i_{1}\right)$, formada também à distância $e$ da superfície refletora, se comporta como um objeto real para o espelho côncavo $(p=2 d-e)$. A distância focal do espelho côncavo é conhecida ( $f_{E}$, igual à metade do raio de curvatura).

De acordo com o enunciado, a imagem desse novo objeto deve se formar no mesmo ponto onde está localizado o objeto original $\left(p^{\prime}=e\right)$. Assim, aplicando-se tais dados na eq.1, temos:

$$
d=\frac{e^{2}}{2\left(e-f_{E}\right)}
$$

Os valores numéricos do exercício $\left(f_{E}=20 \mathrm{~cm}, e=30 \mathrm{~cm}\right)$, se submetidos à eq. 10 , permitem que a resposta indicada no exame como correta seja encontrada $(d=45 \mathrm{~cm})$. Outra possível resolução da questão envolveria considerar que a imagem conjugada pelo espelho côncavo (invertida e formada abaixo de $i_{1}$, mas com o mesmo tamanho desta) se comporta como 
um objeto virtual para o espelho plano, resultando na imagem real observada. Devido ao princípio da reversibilidade dos raios de luz, qualquer uma das soluções descritas é válida.

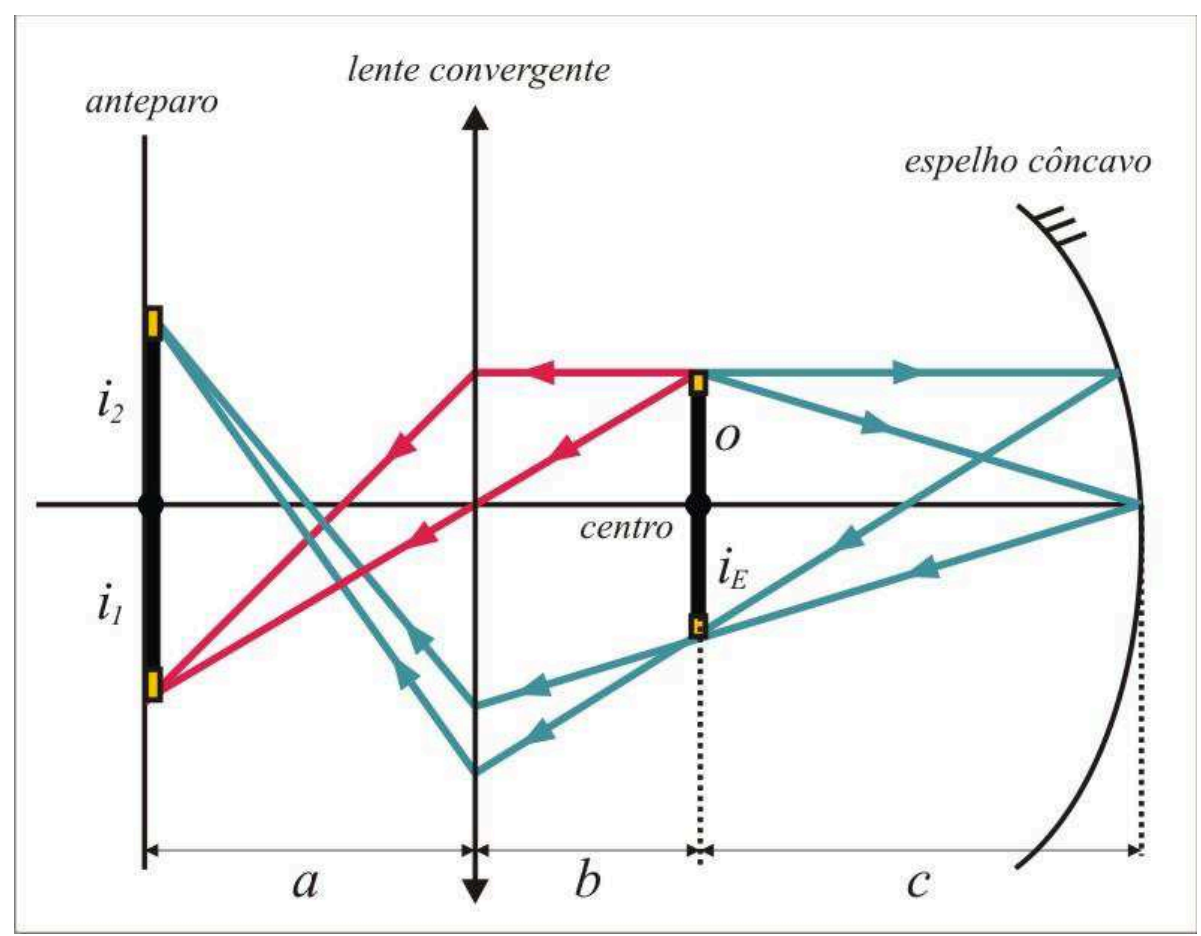

Fig. 3 -Resolução geométrica do problema didático que deu origem à Atividade A.

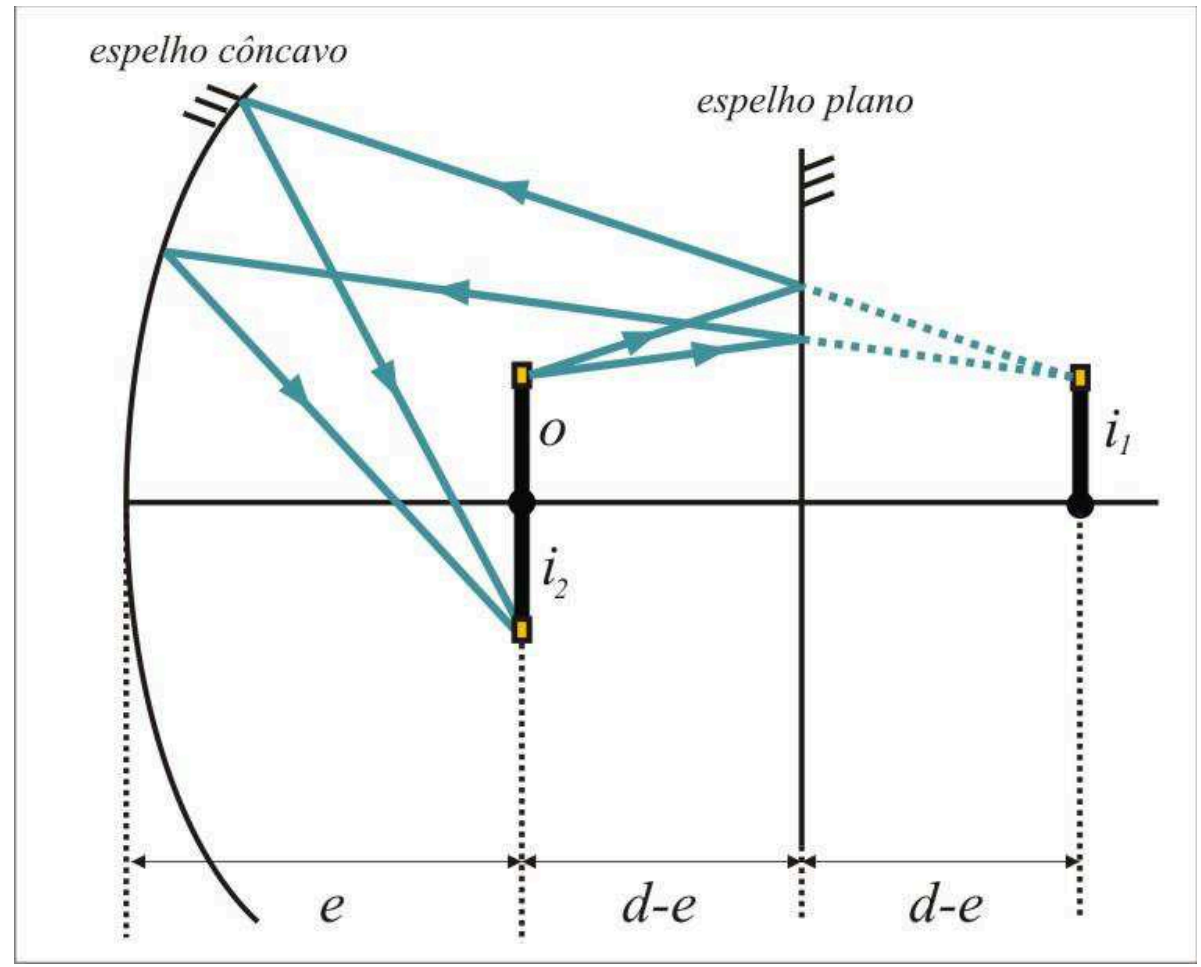

Fig. 4 - Resolução geométrica do problema didático que deu origem à Atividade B. 
Ao contrário do primeiro exercício, uma solução geométrica rápida não é possível para essa questão. É claro que a Fig. 4 representa corretamente a situação, mas se partíssemos da mesma para a determinação da distância $d$, as semelhanças de triângulo necessárias terminariam por levar a um desenvolvimento algébrico equivalente à demonstração da equação de Gauss. A Fig. 4 foi usada como base para a construção do modelo experimental da Atividade B.

\section{Atividades experimentais}

Ambas as situações expostas nos problemas poderiam ser demonstradas experimentalmente com o auxílio de um banco óptico, equipamento tradicional em laboratórios de física. Entretanto, acreditamos que o uso de um equipamento visto como "científico" pelos estudantes poderia levá-los a acreditar que as condições apregoadas pelos exercícios fossem muito específicas e que só poderiam ser provadas com o uso do aparato específico. Assim, decidimos pelo desenvolvimento de experimentos com materiais cotidianos, a fim de que as demonstrações experimentais não fossem submetidas a um novo crivo de desconfiança por parte dos alunos.

Entretanto, foi discutido de forma prévia com os estudantes que o uso de objetos cotidianos traria uma dificuldade: encontrar lentes e espelhos com distâncias focais com valores próximos aos citados nos exercícios didáticos não seria possível no presente trabalho, obrigando a alterações nas respostas numéricas encontradas.

As duas atividades experimentais demandaram o uso de um espelho côncavo de maquiagem, com distância focal aproximada $f_{E}=16 \mathrm{~cm}$. Essa grandeza foi estimada em sala de aula de forma bastante rápida: um celular foi colocado junto à parede, com a sua tela acesa, e o espelho côncavo foi afastado até que uma imagem invertida com o mesmo tamanho do celular fosse projetada abaixo do mesmo. Esse posicionamento evidenciou o raio do espelho, pois somente a imagem de um objeto colocado no centro de um espelho côncavo possui as características descritas. A distância focal $f_{E}$ equivale à metade do raio do espelho estimado.

Um espelho plano de maiores dimensões que o côncavo foi aproveitado na Atividade $B$, e usou-se uma lupa biconvexa comum como lente convergente na Atividade A. A distância focal aproximada $f_{L}$ da lente também foi estimada de forma bastante simples: a lente foi exposta à radiação solar, paralela ao solo. Nessa situação, o quase paralelismo entre os raios de luz oriundos do Sol permite a formação de uma imagem real diminuta do Sol no solo, próxima ao foco, permitindo a medida direta da distância focal. $O$ valor encontrado foi $f_{L}=43 \mathrm{~cm}$.

$\mathrm{O}$ uso de uma vela é tradicional como objeto em experimentos didáticos de projeção de imagens. Contudo, nos inspiramos na proposta de Gore (2012), o qual substitui a vela por uma lanterna de luz LED branca, facilitando a observação das projeções, devido à maior luminosidade emitida pela lanterna. Concebemos um objeto óptico para as atividades experimentais, colocando sobre a lanterna um tubo de vidro vertical, com $9,5 \mathrm{~cm}$ de altura e pequeno diâmetro 
$(0,4 \mathrm{~cm})$ enrolado com fita adesiva transparente ${ }^{2}$. Entretanto, diversos outros objetos poderiam ser utilizados, contanto que obedecessem às condições necessárias ambas as atividades experimentais (simetria e espalhamento da luz emitida pela lanterna em várias direções).

\section{III.1 Montagem experimental - Atividade A}

Tanto a lente quanto o espelho utilizados nesse experimento foram fixados em suportes de metal (Fig. 5). A lente foi disposta a $89,0 \mathrm{~cm}$ de uma parede branca (anteparo de projeção) e a 124,0 cm do espelho côncavo, com seus eixos principais alinhados, conforme o modelo geométrico representado na Fig. 3. Para melhores resultados nas observações, a sala foi escurecida durante o experimento.

Um suporte contendo o objeto foi então colocado entre o espelho e a lente. Após o conveniente alinhamento entre os três elementos, as duas imagens puderam ser observadas no anteparo (Fig. 6) quando o objeto distava 97,0 cm do centro óptico da lente e 29,0 cm do vértice do espelho. Foi verificado que o tamanho da imagem invertida foi de $8,2 \mathrm{~cm}$ (o valor esperado era $8,7 \mathrm{~cm})$. Foi percebido que a imagem direita era um pouco menor que a invertida $(7,9 \mathrm{~cm})$, provavelmente porque devido à sua melhor luminosidade, seu extremo era mais difícil de ser visualizado.

Durante a realização do experimento, algumas variantes do uso do aparato experimental foram testadas. Nossa solução teórica apontou que duas imagens poderiam ser superpostas no anteparo se o objeto e o espelho estivessem na mesma posição. Assim, o espelho foi colocado o mais próximo possível do objeto, o qual foi mantido a 97,0 cm (ibid), para que a imagem conjugada diretamente pela lente continuasse nítida no anteparo. Foi observada a conjugação de uma segunda imagem invertida um pouco maior que a primeira e superposta a esta, mas não possuindo a mesma nitidez da imagem original. Assim, a projeção final se tornou um borrão difuso, e as dificuldades de obtenção de uma boa fotografia nas condições de quase escuridão inviabilizaram o registro dessa imagem. Apesar disso, os estudantes que observaram diretamente essa superposição conseguiram distinguir as duas imagens superpostas.

Outra variante no experimento envolveu cobrir o espelho com a mão, levando ao desaparecimento da imagem direita, evidenciando-se a necessidade do retorno da luz refletida pelo espelho à lente convergente para a formação da segunda imagem na tela. Uma última possibilidade de investigação veio da percepção que alguns estudantes apresentaram sobre a não observação da imagem intermediária $i_{E}$, levando a questionamentos sobre a sua existência (Fig. 3). Foi então colocada uma folha de papel diretamente abaixo do objeto, e a imagem invertida conjugada pelo espelho côncavo foi ali observada.

\footnotetext{
${ }^{2}$ A transparência do cilindro de vidro não permitia o espalhamento da luz, razão pela qual ele foi enrolado com fita adesiva transparente.
} 


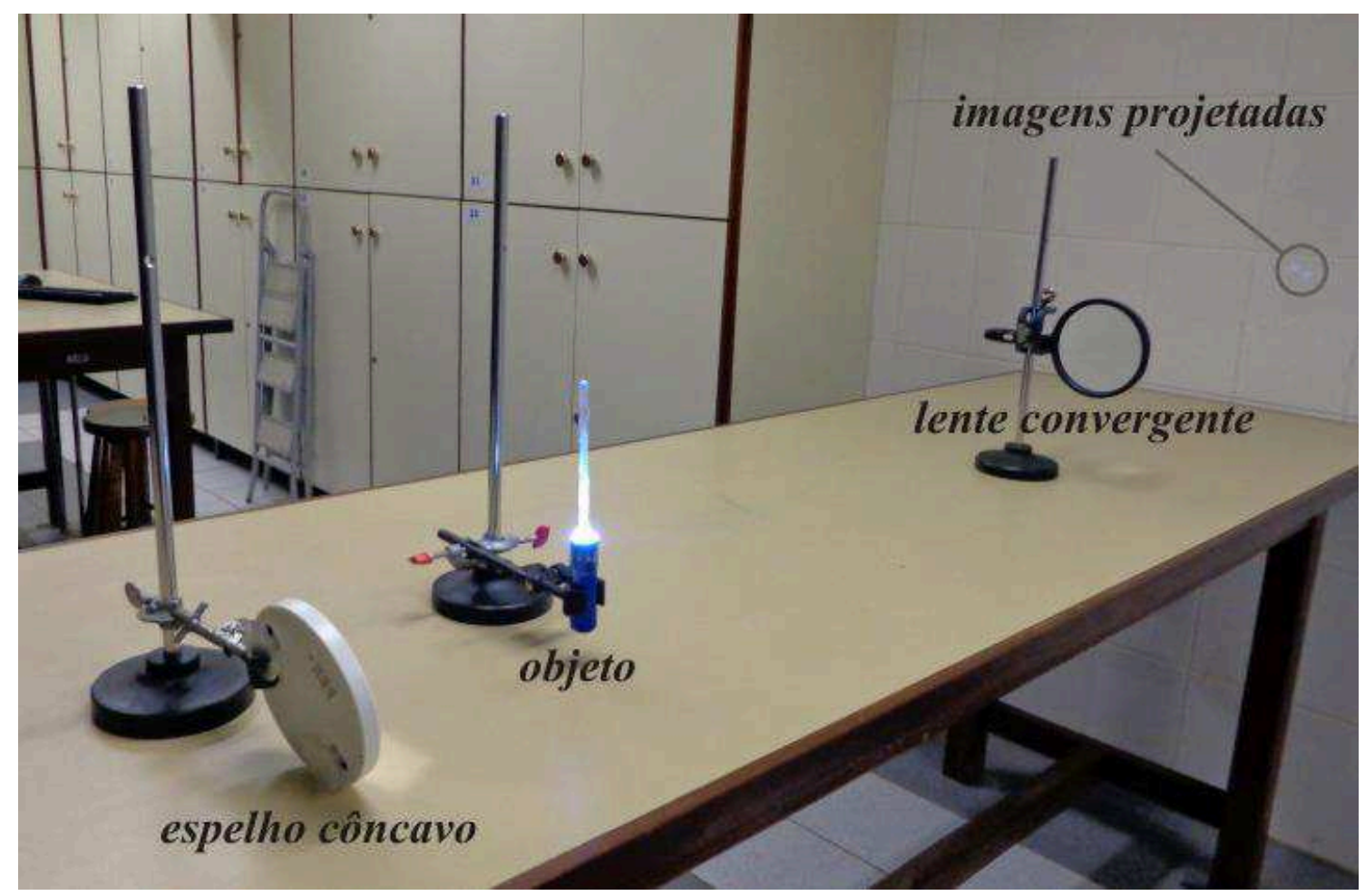

Fig. 5 - Montagem experimental da Atividade A.

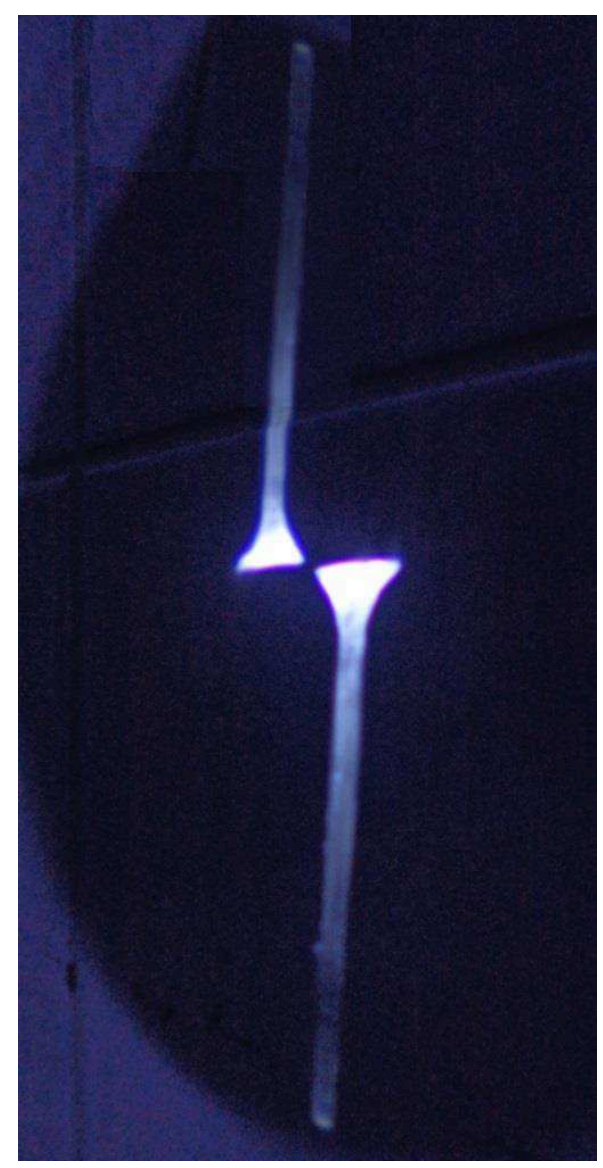

Fig. 6-Projeção da imagem dupla do objeto na Atividade A. 


\section{III.2 Montagem experimental - Atividade B}

Assim como na primeira atividade prática, o espelho côncavo e o plano tiveram seus eixos convenientemente alinhados, e foram dispostos a 35,0 cm de distância entre si, conforme representado na Fig. 2. Os mesmos objetos ópticos foram colocados entre os dois elementos, acrescidos de uma tira vertical de papel disposta abaixo do objeto, para fins de projeção da imagem invertida $i_{2}$ (Fig. 8). Quando o objeto estava localizado a 22,0 cm do espelho côncavo, a imagem esperada foi detectada na tira de papel, a qual não é observada na Fig. 7 por estar localizada atrás da lanterna, no ângulo em que a fotografia foi obtida.

Os estudantes foram questionados sobre a possibilidade de a imagem observada ser formada apenas pelo espelho côncavo, sem a necessidade da presença do espelho plano. Para demonstrar tal impossibilidade, o espelho plano foi coberto com a mão e a imagem projetada abaixo do objeto desapareceu, sendo substituída por um borrão resultante da luz refletida no espelho côncavo.

Um registro fotográfico nítido da imagem obtida nesse experimento foi complexo de ser obtido, pois a câmera foi posicionada de forma a receber luz tanto do objeto quanto da sua imagem virtual no espelho plano, resultando em um brilho muito intenso para essas fontes quando comparado à luminosidade exibida pela imagem projetada na tira de papel (Fig. 8).

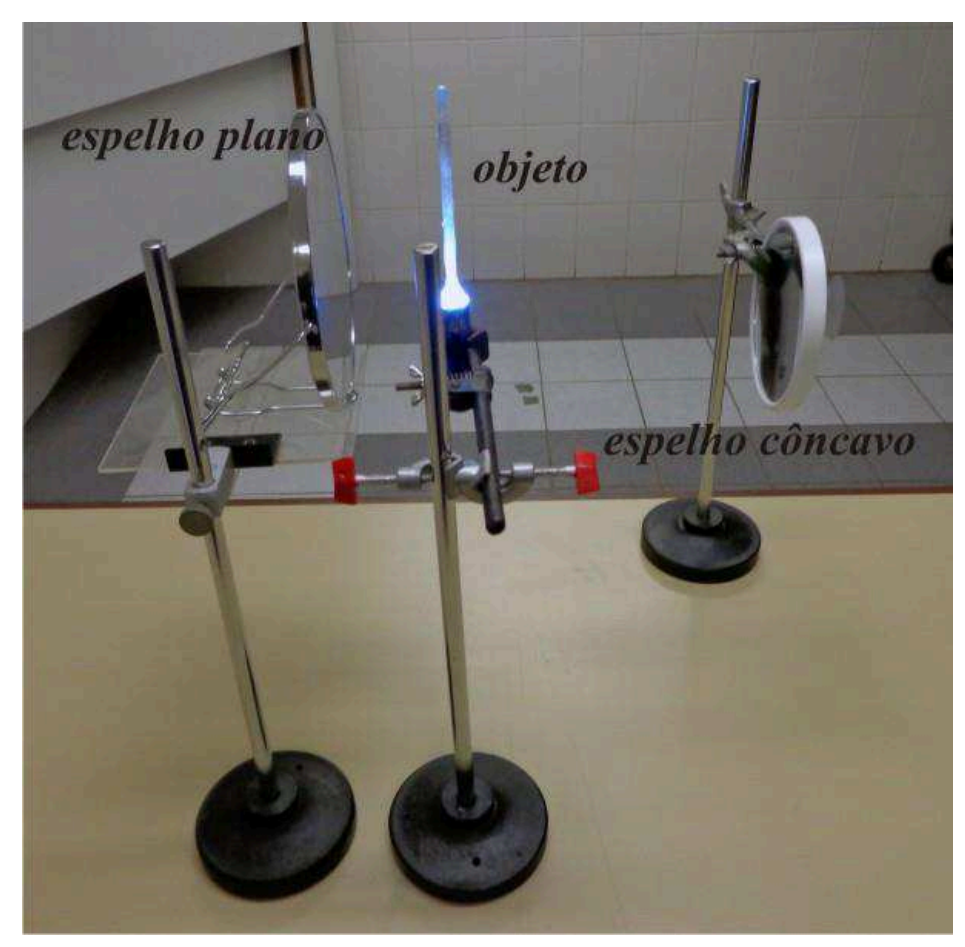

Fig. 7 - Montagem experimental da Atividade B. 


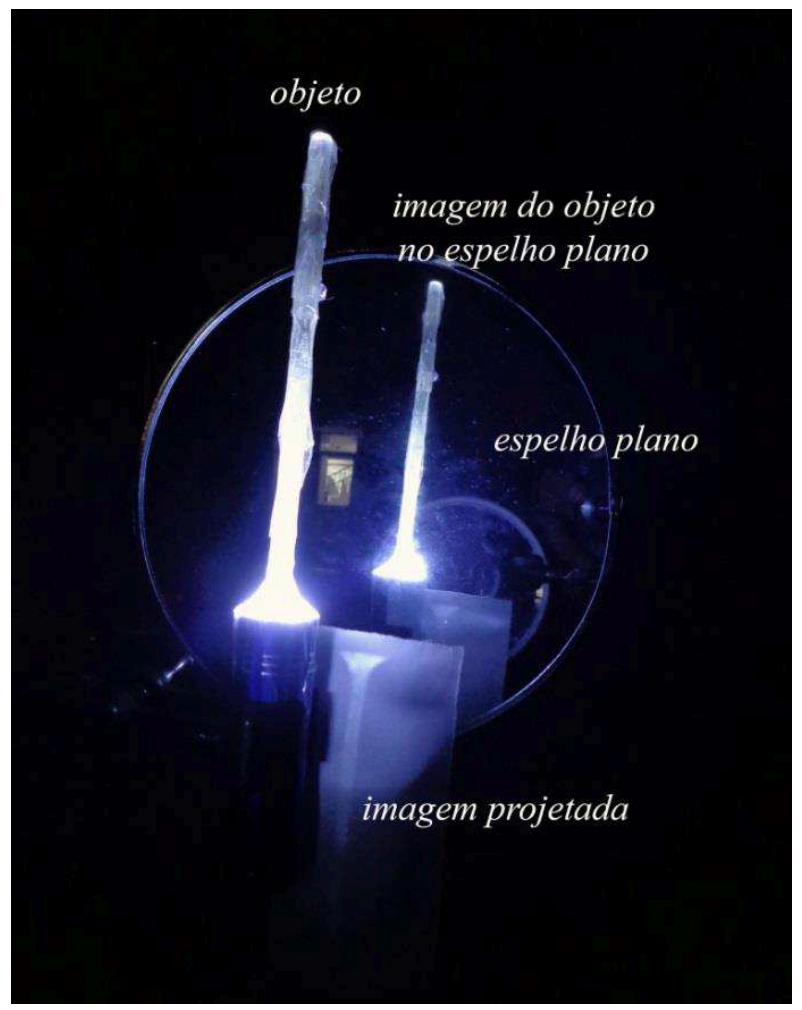

Fig. 8 - Projeção da imagem invertida abaixo do objeto na Atividade $B^{3}$.

A Fig. 8 traz um problema de ordem conceitual: a fotografia parece demonstrar que a imagem projetada é menor que o objeto utilizado. Durante o experimento, entretanto, percebemos que o tamanho da imagem era quase idêntico ao do objeto, mas seu brilho era muito mais fraco. Ao fotografarmos a cena, o modo automático de medição de intensidade luminosa da câmera foi influenciado pelo brilho do objeto e da imagem virtual, realçando as dimensões destes em relação às da imagem projetada, cujo brilho mais fraco quase não foi captado. Esse fato criou um problema não intencional na fotografia, na qual o tamanho da imagem é muito inferior ao do objeto, quando a observação direta demonstrava a igualdade entre suas dimensões.

Uma estimativa da distância focal do espelho côncavo pode ser feita com facilidade nesse experimento: ao se retirar o espelho plano, pode-se projetar uma imagem invertida e de mesmo tamanho do objeto na tira de papel se o espelho curvo for adequadamente disposto (o objeto deve estar localizado no seu centro de curvatura). Ao realizarmos essa variação, o valor obtido para a distância focal $f_{E}$ coincidiu com o estimado anteriormente com o aparelho celular $(16,0 \mathrm{~cm})$.

\footnotetext{
3 Na imagem, é possível observar uma pequena mancha luminosa ao lado do objeto, que corresponde à porta envidraçada do laboratório onde os experimentos foram realizados.
} 


\section{Discussão dos resultados}

Quando comparadas com os exercícios didáticos que lhes deram origem, as atividades experimentais apresentaram os resultados esperados, mas com algumas adaptações. A principal modificação se relacionou com a necessidade de se projetar as imagens com um leve desvio lateral, como as Fig. 6 e 8 demonstram, devido ao fato da lanterna usada como fonte luminosa bloquear os raios de luz refletidos pelo espelho côncavo, resultando na ausência da imagem no anteparo na Atividade A e na projeção direta sobre a própria lanterna na Atividade B. Essa modificação, entretanto, não chegou a ser questionada pelos estudantes durante as demonstrações.

O experimento foi feito de forma demonstrativa, devido a restrições de equipamento: cada turma da instituição de ensino possui em média quarenta alunos, os quais se dividem no laboratório em grupos (quatro a cinco integrantes). Seria necessário, portanto, adquirir ao menos dez conjuntos de lentes, espelhos e suportes para os experimentos, tornando a demonstração experimental inviável do ponto de vista financeiro. Assim, os alunos não participaram diretamente da montagem, devido ao caráter demonstrativo da atividade.

Ambos os experimentos foram apresentados aos estudantes em uma única aula simples (cinquenta minutos). A sequência de cada experimento foi a seguinte: um projetor digital foi usado para apresentar o problema original, e o professor desenvolveu tanto a solução geométrica quanto a algébrica do mesmo no quadro branco. Nesse desenvolvimento, alguns valores numéricos foram alterados, tais como a distância focal da lente e do espelho e a distância entre tais elementos, para compatibilização com os dados reais da aparelhagem. Em seguida, a atividade demonstrativa foi realizada, conforme descrita no item anterior, no qual é detalhada a interação com os estudantes e alguns questionamentos levantados pelos mesmos.

Admitimos que as falas dos estudantes não foram gravadas ou filmadas, razão pela qual não estão presentes de forma sistemática nesse tópico. Algumas colocações mais marcantes feitas pelos alunos estão expostas na descrição das atividades experimentais e nas conclusões desse artigo. Assim, para fins de maior precisão terminológica, tem-se aqui um relato da nossa percepção diante do acontecimento educacional. A discussão dos resultados citada, portanto, não se adequa à situação pedagógica em si, mas sim aos resultados numéricos do experimento, assim como os aspectos qualitativos possíveis de identificação.

Para o teste quantitativo do modelo teórico, as distâncias entre o objeto e os elementos ópticos foram medidas por nós, com uma régua comum. Consideramos que os percentuais de erro foram aceitáveis, como descritos a seguir.

Na Atividade A, que versava sobre a formação da imagem dupla, o objeto deveria estar localizado no centro do espelho côncavo $(32,0 \mathrm{~cm})$ e as imagens eram mais nítidas quando $c=29,0 \mathrm{~cm}$ (diferença de $9 \%$ em relação à estimativa inicial). Se a distância entre o objeto e a lente $(b=97 \mathrm{~cm})$ e a distância entre a imagem e a lente $(a=89,0 \mathrm{~cm})$ forem aplicadas na eq. 3, o valor da distância focal da lente será estimado como 46,4 cm (diferença de 10\%).

Já na Atividade $B$, se forem colocados na eq.10 os valores para a distância entre os espelhos $(d=35,0 \mathrm{~cm})$ e a distância entre o objeto e o espelho côncavo $(\mathrm{e}=22,0 \mathrm{~cm})$, obtém- 
se uma distância focal igual a 15,1 cm (diferença de $16 \%$ em relação à estimativa original). Consideramos essas diferenças percentuais nas duas atividades como admissíveis, devido à simplicidade do modelo experimental e também pelo fato de não ser possível esperar que a lente convergente e o espelho côncavo obedeçam às condições de Gauss com total precisão, dado o caráter aproximativo das equações desenvolvidas a partir dessas condições.

\section{Conclusões e perspectivas}

Uma das vantagens de se trabalhar com os modelos da óptica geométrica no ensino médio é a facilidade de se realizar demonstrações experimentais. As atividades sugeridas nesse artigo são de baixo custo, facilmente desenvolvidas pelo professor ou pelos estudantes, não apresentam necessidade de manutenção, são lúdicas e interessantes como ponto de discussão com os estudantes, são portáteis e ilustram corretamente os tópicos discutidos. A nosso ver, tais características são algumas das mais desejáveis em atividades experimentais voltadas para o ensino médio.

O ensino de ciências centrado no trabalho laboratorial tem sido fruto de diversos reexames nas últimas décadas (HODSON, 1994; LABURÚ et al., 2007; BORGES, 2002). Seus críticos apontam para a necessidade de uma reavaliação do papel dos experimentos na aprendizagem. Nesse contexto, acreditamos que a confecção de atividades experimentais que dialoguem com exercícios didáticos possa vir a contribuir para a aprendizagem, por permitir que um problema possa ser abordado por diversas frentes de trabalho (solução geométrica, solução algébrica, teste experimental), em uma extensão do potencial didático dos mesmos.

Após a leitura dos pareceres desse artigo, percebemos que as atividades experimentais descritas apresentavam algumas inconsistências metodológicas, que poderiam ter sido minimizadas com alterações no aparato ou método de coleta de dados. Por exemplo, não tomamos o cuidado de determinar os erros de medida das distâncias focais do espelho e da lente utilizados, e este erro poderia definir se os resultados quantitativos obtidos são aceitáveis. Equipamentos mais precisos, tais como bancos ópticos tradicionais, poderiam ajudar a minimizar esses erros, permitindo uma verificação da validade quantitativa das leis físicas utilizadas. Admitimos também que o método para a medida da distância focal do espelho côncavo, descrito na seção 3, é apenas a repetição do procedimento utilizado inicialmente (projeção da imagem do celular com a tela acesa). Assim, o uso de métodos mais precisos para determinar as distâncias focais do espelho e da lente poderia fornecer um maior rigor científico aos experimentos, fato tão importante quanto buscar um novo significado para as atividades experimentais em física no ensino básico.

Alguns estudantes que observaram as imagens produzidas na Atividade A (Fig. 6) em detalhe relataram que a imagem invertida, conjugada apenas pela lente, apresentava um contorno azulado. Já para a imagem direita, conjugada pelo espelho e lente, o contorno possuía uma coloração magenta (a Fig. 6 apresenta a imagem captada pela câmera, a qual apresenta inconsistências com esse relato, devido às limitações do sensor fotoelétrico do aparelho). Não 
nos dedicamos a elaborar uma explicação detalhada para esse fenômeno, o qual está relacionado com a dispersão luminosa, devido à refração da luz branca na lente convergente e a consequente formação de sombras coloridas. O trabalho de Yurumezoglu (2009) fornece pistas para a elucidação desse fenômeno.

Exercícios didáticos e atividades experimentais são algumas das searas mais exploradas em cursos de física no ensino básico e também no superior. Apesar disso, a comunicação direta entre essas atividades pedagógicas é rara, quando não ausente por completo. $\mathrm{O}$ trabalho de laboratório muitas vezes é desconectado do trabalho teórico centrado em exercícios didáticos até mesmo na fase de avaliação e valoração: é comum, tanto no ensino superior quanto no médio, que haja disciplinas distintas para o trabalho teórico e experimental em física. Assim, acreditamos que devem ser buscadas novas oportunidades capazes de vincular essas duas técnicas de aprendizagem, tão fundamentais e complementares para a construção do conhecimento em ciências.

\section{Referências bibliográficas}

BORGES, T. Novos rumos para o laboratório escolar de ciências. Caderno Brasileiro de Ensino de Física, v. 19, n. 3, p. 291-313, 2002. Disponível em: <https://www.rbcdh.ufsc.br/index.php/fisica/article/viewFile/6607/6099>. Acesso: 20 out. 2015.

GORE, G. Another way to experiment with images formed by lenses. The Physics Teacher, v. 50, n. 5, p. 314, 2012. Disponível em: <http://dx.doi.org/10.1119/1.3703557> Acesso: 20 out. 2015.

HALliDAY, D.; RESNICK, R.; WALKER, J. Fundamentals of Physics. 9. ed. New York: John Wiley \& Sons, 2011. p. 925-957.

HETCH, E. Optics. 4. ed. Pearson: Glenview, 2002. p.258-281.

HODSON, D. Hacia un enfoque más crítico del trabajo de laboratório. Enseñanza de las Ciencias, v. 12, n. 3, p. 299-313, 1994.

INSTITUTO TECNOLÓGICO DE AERONÁUTICA (ITA). Processo de seleção - Instituto Tecnológico de Aeronáutica - Física - 1997, p. 4, São José dos Campos, 1997. Disponível em: < http://www.ebah.com.br/content/ABAAABNncAJ/ita-1997 >. Acesso: 01 jun. 2015.

LABURÚ, C.; BARROS, M.; KANBACH, B. A relação com o saber profissional do professor de Física e o fracasso da implementação de atividades experimentais no ensino médio. Investigações em Ensino de Ciências, v. 12, n. 3, p.305-320, 2007. Disponível em: <http://www.if.ufrgs.br/public/ienci/artigos/Artigo_ID172/v12_n3_a2007.pdf >. Acesso: 20 out. 2015.

NUSSENZVEIG, H. Curso de física básica. 1. ed. São Paulo: Blucher, 1998. p.18-24. v. 4. 
PIETROCOLA, M.; POGIBIN, A.; OLIVEIRA, R.; ROMERO, T. Física em contextos: pessoal, social e histórico: energia, calor, imagem e som: volume 2. 1. ed. São Paulo: FTD, 2011. p. 355-404.

RAMALHO, F.; FERRARO, N.; TOLEDO, P. Os fundamentos da Física - Termologia, Óptica e Ondas. 9. ed. São Paulo: Moderna, 2007. p. 260-283. v. 2.

RODRIGUES, E. Uma revisão da questão da garrafa PET da prova ENEM 2013. Caderno Brasileiro de Ensino de Física, v. 31, n. 2, p. 421-428, 2014. Disponível em: $<$ https://www.rbcdh.ufsc.br/index.php/fisica/article/viewFile/2175-7941.2014v31 n2p421/27327>. Acesso: 20 out. 2015.

SILVA, C.; BARRETO, B. Física aula por aula. 1. ed. São Paulo: FTD, 2008. p. 285-296. v. 2 .

SILVEIRA, F.; ENDLER, A.; CARLI, E. Um barco a vela pode ser propulsionado por um ventilador solidário ao barco que sopra em sua vela? Caderno Brasileiro de Ensino de Física, v. 32, n. 1, p. 278-286, 2015. Disponível em: <https://periodicos.ufsc.br/ index.php/fisica/article/download/2175-7941.2015v32n1p278/29047>. Acesso: 20 out. 2015.

UNIVERSIDADE FEDERAL DO ESPÍRITO SANTO (UFES). Processo Seletivo 2004, Prova 2 - Física, Biologia, Língua Portuguesa e Literatura Brasileira, Língua Estrangeira, p. 3, Vitória, CCV/UFES, 2004.

YURUMEZOGLU, K. An entertaining method of teaching concepts of linear light propagation, reflection and refraction using a simple optical mechanism. Physics Education, v. 44, n. 2, p. 129-132, 2009. Disponível em: <http://iopscience.iop.org/ 0031-9120/44/2/002> Acesso: 20 out. 2015.

ZÍLIO, S. Óptica geométrica paraxial. In: (Ed.) Óptica moderna: fundamentos e aplicações. 1. ed. São Carlos: Instituto de Física de São Carlos, 2009. cap. 1. p. 1-52. 